\title{
Microelectrode Arrays Modified with Nafion/Nanoporous AuPt Nanoparticles for in vivo Detection of Dopamine
}

\author{
Zongya Zhao, ${ }^{1}$ Zhongwei Li, ${ }^{1} \mathrm{Wu}$ Ren, ${ }^{1}$ Qiongqiong Ren, ${ }^{1}$ \\ Ruxue Gong, ${ }^{2}$ Juntang Lin, ${ }^{1}$ and $\mathrm{Yi} \mathrm{Yu}^{1}{ }^{*}$ \\ ${ }^{1}$ School of Biomedical Engineering, Xinxiang Medical University, Xinxiang 453003, China \\ ${ }^{2}$ Institute of Biomedical Engineering, School of Life Science and Technology, \\ Xi'an Jiaotong University, Xi'an 710049, China
}

(Received January 5, 2018; accepted March 22, 2018)

Keywords: in vivo dopamine detection, nanoporous AuPt alloy nanoparticles, microelectrode arrays

Electrochemical determination using implantable microelectrode arrays provides a powerful tool for recording neurotransmitter concentrations across multiple spatial locations of brain tissue. In this study, nanoporous AuPt alloy nanoparticles with very rough surfaces and Nafion film were sequentially electrodeposited on Michigan-type microelectrode arrays to improve sensitivity and selectivity to dopamine (DA). The modified microelectrode arrays were characterized by scanning electron microscopy (SEM), X-ray diffractometry, cyclic voltammetry (CV), and amperometry. The results of SEM experiments indicated that the obtained AuPt alloy nanoparticles with many different sizes of pores possessed very rough surfaces and exhibited cauliflower-like shapes. During amperometric measurements, the constructed DA sensors showed a wide linear range of $0.05-12.05 \mu \mathrm{M}$ with a high sensitivity of $73.4 \pm 3.1 \mathrm{pA} / \mu \mathrm{M}$. Other important features include a low detection limit of $25 \mathrm{nM}$ (signalto-noise ratio: 3), excellent selectivity over ascorbic acid (AA), and good stability. The feasibility of in vivo DA detection using the modified microelectrode arrays was verified by recording electrically evoked DA in the striatum of rats. The developed DA sensors based on microelectrode arrays provide an important tool for electrochemical detection of in vivo DA.

\section{Introduction}

The rapid application and development of micro-electromechanical systems (MEMS) technology in various fields enabled the fabrication of microelectrode arrays with highly reproducible geometrical and electrical characteristics. The researchers could precisely define microelectrode parameters, such as electrode shape, size, and site position, by using MEMS technology and could fabricate multiple stimulation/recording sites on a single microelectrode shank. $^{(1)}$ The microelectrode arrays are a powerful tool for recording the electrical activity of nerve cells and helping researchers to further study information flow principles in the nervous system. In addition to recording electrophysiological signals, with the use of certain

*Corresponding author: e-mail: dakeji_2006@126.com http://dx.doi.org/10.18494/SAM.2018.1893 
microelectrode materials, these microelectrode arrays could be used to detect neurotransmitter levels in the extracellular space by electrochemical techniques. ${ }^{(2-6)}$

It is well known that many central nervous diseases, including Parkinson's disease (PD), are caused by irregular dopamine (DA) concentrations. Therefore, recording DA concentrations in animal models has become a powerful methodology for understanding the mechanisms of and therapies for these diseases. One of the most important factors that should be taken into consideration in developing in vivo DA electrochemical sensors is selectivity. This factor is very important because major sources of interference, such as ascorbic acid (AA), also exist in body fluids together with DA and show very high concentrations with similar oxidization potentials to that of DA. Hence, a variety of composites, such as tyrosinase-based materials, ${ }^{(7)}$ ion-exchange membranes, ${ }^{(8,9)}$ conducting polymer films, ${ }^{(10)}$ and molecularly imprinted polymer, ${ }^{(11)}$ have been used to enhance the selectivity of DA detection. It is well known that the cation exchange polymer, Nafion, possesses the ability to repel negative ions and combine with positively charged species, because of the appearance of anionic sites in its structure. In the physiological environment $(\mathrm{pH}=7.4)$, DA is a positively charged molecule ( $p K_{B}=8.87$ ), whereas AA exists in the negatively charged form $\left(p K_{A}=4.10\right)$. Therefore, Nafion has been one of the popular materials to improve the electrode selectivity to DA. ${ }^{(12-14)}$

Another important factor for developing in vivo DA electrochemical sensors is the sensitivity. Because the sensitivity of an electrochemical sensor is directly related to the electrode surface area and conductivity, a variety of nanostructured materials, such as metal oxide nanoparticles, ${ }^{(15-17)}$ carbon nanotubes, ${ }^{(18,19)}$ metal or bimetallic nanoparticles, ${ }^{(20-23)}$ graphene, ${ }^{(24-26)}$ and nanocomposites, ${ }^{(27,28)}$ have been proposed to modify the electrode. Recently, AuPt alloy nanoparticles have become the current focus of research and have gained a wide range of applications in various fields, including electrochemical sensors, ${ }^{(20,29,30)}$ fuel cells, ${ }^{(31)}$ and Raman scattering. ${ }^{(32)}$ AuPt alloy nanoparticles exhibited a variety of excellent performances including promoted electron transfer rate, increased electrocatalytic activity, and improved surface area compared with corresponding $\mathrm{Au}$ or Pt monometallic nanoparticles, and these favorable characteristics are mainly due to the synergistic effects of $\mathrm{Au}$ and $\mathrm{Pt}$ monometallic nanoparticles. For example, Liu et al. prepared AuPt bimetallic nanoclusters on electrochemically reduced graphene oxide (GO) for sensitive detection of DA. ${ }^{(29)}$ Our group also applied a one-step electrochemical approach to prepare cauliflower-like AuPt alloy nanoparticle-graphene nanocomposites for fabricating DA sensors. ${ }^{(20)}$ However, it is believed that surface morphology is one of the most important factors that greatly influences the electrochemical properties of nanoparticles, and nanoparticles possessing different surface morphologies might exhibit different properties. ${ }^{(33)}$ Recently, porous materials have gained significant research attention because the presence of micropores or nanopores could drastically increase the surface area and enhance the electrochemical reaction rate. For example, Chen et al. prepared porous PdAg alloy nanoflowers on reduced GO for simultaneous in vitro determination of AA, DA and uric acid. ${ }^{(34)}$ However, to the best of our knowledge, there is no report on the application of Nafion film/nanoporous AuPt nanoparticles fabricated with an electrochemical method to modify gold microelectrode arrays for use in electrochemical in vivo DA detection. 
Here, in order to construct in vivo DA electrochemical sensors on Michigan-type silicon electrodes fabricated by our group, ${ }^{(35)}$ firstly, Au microelectrode sites with a diameter of 50 $\mu \mathrm{m}$ (round) were modified by electro-codeposition of $\mathrm{Au}-\mathrm{Pt}-\mathrm{Cu}$ trimetallic nanoparticles followed by chemical etching of the $\mathrm{Cu}$ component from the trimetallic nanoparticles. Then, Nafion film was electropolymerized on the modified gold microelectrode sites. Finally, various techniques, including scanning electron microscopy (SEM), X-ray diffraction (XRD) analysis, cyclic voltammetry (CV), amperometry, and in vivo DA detection, were used to characterize the constructed DA sensors. Results indicated that the obtained AuPt alloy nanoparticles with many different sizes of pores possessed very rough surfaces and exhibited cauliflower-like shapes, and the constructed DA sensors showed a wide linear range of $0.05-12.05 \mu \mathrm{M}$ of detection with a high sensitivity of $73.4 \pm 3.1 \mathrm{pA} / \mu \mathrm{M}$. More importantly, preliminary animal experiments showed that our developed DA sensors could record electrically evoked DA concentration change signals in the brain of anesthetized rats by stimulating the medial forebrain bundle (MFB).

\section{Experiment}

\subsection{Fabricated microelectrode arrays}

The fabricated Michigan-type silicon electrodes possessed 14 round Au microelectrode sites on each side of the electrode shrank and had the dimensions of $200 \mu \mathrm{m} \times 400 \mu \mathrm{m} \times 9 \mathrm{~mm}(t \times$ $w \times 1)$. There are three kinds of microelectrode sites: three sites with diameter of $100 \mu \mathrm{m}$ for stimulation, seven sites with diameter of $20 \mu \mathrm{m}$ for electrophysiological recording, and four sites with diameter of $50 \mu \mathrm{m}$ for preparing neurotransmitter sensors.

As shown in Fig. 1, the fabricated microelectrode arrays showed a needlelike structure, the yellow round spots are bare $\mathrm{Au}$ sites with different diameters, and the dark brown lines are $\mathrm{Au}$ conductive wires whose surfaces are covered with an $\mathrm{SiO}_{2}$ insulating layer. The yellow squares at the end of the microelectrode array are also bare Au sites that are connected with a printed circuit board by gold wire bonding technology. All other parts of the microelectrode array are covered with an $\mathrm{SiO}_{2}$ insulating layer. The detailed description of the design and fabrication of the microelectrode arrays was given in our group's previous work. ${ }^{(35)}$ In this study, the neurotransmitter measurement sites with diameter of $50 \mu \mathrm{m}$ were modified with Nafion film/ nanoporous AuPt nanoparticles used as DA sensors and their performance was mainly studied.

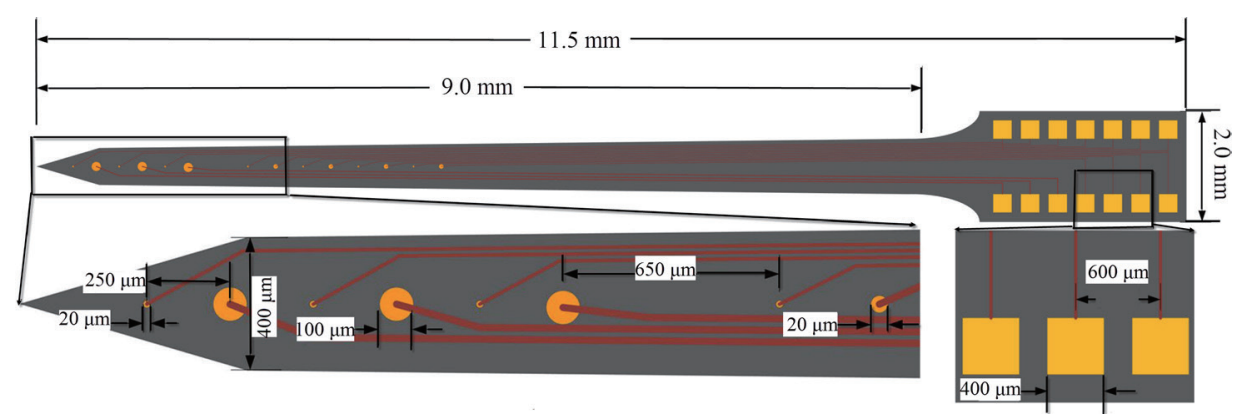

Fig. 1. (Color online) Schematic diagram of the designed microelectrode array. 


\subsection{Materials and equipment}

Nafion solution (5\%, Du Pont 110EW Nafion), DA, AA, and 3,4-dihydroxyphenylacetic acid (DOPAC) were purchased from Enzyme-Linked Biotechnology Co., Ltd. (Shanghai, China). Chloroplatinic acid hexahydrate $\left(\mathrm{H}_{2} \mathrm{PtCl}_{6} \cdot 6 \mathrm{H}_{2} \mathrm{O}\right)$ was obtained from Aladdin Industrial Inc. (Shanghai, China). Chloroauric acid tetrahydrate $\left(\mathrm{HAuCl}_{4} \cdot 4 \mathrm{H}_{2} \mathrm{O}\right)$ was obtained from Sangon Biotech. Co., Ltd. (Shanghai, China). All other reagents were of analytical grade, and could be used without further purification. Ultrapure water (Millipore, $\geq 18 \mathrm{M} \Omega \mathrm{cm}$ ) was used to prepare all aqueous solutions. $\mathrm{NaH}_{2} \mathrm{PO}_{4}(0.1 \mathrm{~mol} / \mathrm{L})$ and $\mathrm{Na}_{2} \mathrm{HPO}_{4}(0.1 \mathrm{~mol} / \mathrm{L})$ mixed at different ratios were used to prepare phosphate buffer solution $(\mathrm{PBS}, 0.1 \mathrm{~mol} / \mathrm{L}$ ) with different $\mathrm{pH}$ values.

$\mathrm{CV}$ and amperometry experiments were carried out using a $\mathrm{CHI} 650 \mathrm{E}$ potentiostat with a microcurrent amplifier (Chenhua Instrument Company, Shanghai, China). A conventional three-electrode configuration, which included a working electrode (the modified microelectrode array), a $\mathrm{Ag} / \mathrm{AgCl}(3 \mathrm{M} \mathrm{KCl})$ reference electrode, and an auxiliary electrode (a platinum wire), was used in all in vitro electrochemical experiments.

SEM experiments were carried out on a Jsm-7800f field emission scanning electron microscope (Electro Co., Tokyo, Japan). An X'PertProPANalytical diffractometer with $\mathrm{Cu} \mathrm{K \alpha}$ radiation $(\lambda=0.15418 \mathrm{~nm})$ was applied to obtain XRD patterns.

\subsection{Preparation of Nafion/nanoporous AuPt nanoparticle-modified microelectrodes}

There are about four steps in the preparation of Nafion/nanoporous AuPt-nanoparticlemodified microelectrode arrays. Firstly, bath sonication was used to clean the microelectrode arrays in ethanol (1:1) and ultrapure water in sequence. Secondly, $\mathrm{Au}-\mathrm{Pt}-\mathrm{Cu}$ trimetallic nanoparticles were electrochemically codeposited on the gold sites (diameter of $50 \mu \mathrm{m}$ ) of the fabricated microelectrode arrays using a conventional three-electrode configuration at room temperature. Electro-codeposition of $\mathrm{Au}-\mathrm{Pt}-\mathrm{Cu}$ trimetallic nanoparticles was carried out at $-0.25 \mathrm{~V}$ for about $600 \mathrm{~s}$ in a mixed solution containing $0.5 \mathrm{mM} \mathrm{H}_{2} \mathrm{PtCl}_{6}, 0.25 \mathrm{mM} \mathrm{CuSO}_{4}$, and 0.5 $\mathrm{mM} \mathrm{HAuCl} 4$ prepared with $0.5 \mathrm{M} \mathrm{H}_{2} \mathrm{SO}_{4}$ solution. Thirdly, the $\mathrm{Cu}$ component in the $\mathrm{Au}-\mathrm{Pt}-$ $\mathrm{Cu}$ trimetallic nanoparticles was selectively etched in $60 \% \mathrm{HNO}_{3}$ at $70{ }^{\circ} \mathrm{C}$ for about one hour ${ }^{(36)}$ to obtain nanoporous AuPt alloy nanoparticles. Finally, the gold microelectrode sites modified with AuPt alloy nanoparticles underwent electropolymerization of the cation exchange polymer Nafion at $+0.50 \mathrm{~V}$ for the optimal duration of $100 \mathrm{~s}$. After that, the microelectrode arrays were immediately dipped in distilled water for $10 \mathrm{~s}$ to remove additional Nafion and then baked at $200{ }^{\circ} \mathrm{C}$ for $5 \mathrm{~min}$ to form a stable film. For comparison, Nafion-modified bare sites and Nafion/ Au nanoparticles (AuNPs)-modified sites were also prepared under similar conditions.

\subsection{In vivo detection of $\mathrm{DA}$}

Preliminary animal experiments were performed to verify the feasibility of in vivo DA detection of our developed DA sensors. Male Sprague-Dawley (SD) rats (250-300 g) from the Laboratory Animal Center of Xinxiang Medical University were used in the in vivo 
DA detection experiments. The protocols of all animal experiments were approved by the animal ethics committee of Xinxiang Medical University. The SD rats were anesthetized by intraperitoneally injecting $3 \%$ pelltobarbitalum natricum $(0.3 \mathrm{~mL} / 100 \mathrm{~g})$ and fixed in a rat brain stereotaxic system.

For in vivo DA recordings, three electrodes were applied per rat, namely, the constructed DA sensor sites on microelectrode arrays as the working electrode (WE), a $\mathrm{Ag} / \mathrm{AgCl}$ microwire as the reference electrode (RE), and a Pt microwire as the counter electrode (CE). The WE was implanted into the left striatum (AP: +1.2, ML: 2.0, DV: 4.6-6.0). The RE and CE were in contact with the dura in the contralateral hemisphere (AP: +1-3, ML: 3-4). The amperometry technique with oxidation potential at $+0.3 \mathrm{~V}$ vs $\mathrm{Ag} / \mathrm{AgCl}$ was used to record the DA concentration in rat brain. In addition, a monopolar stimulating electrode (tungsten wire, diameter: $127 \mu \mathrm{m}$, Teflon coated, A-M Systems) was inserted into the left MFB (AP: $-4.4 \mathrm{~mm}$, ML: $+0.8 \mathrm{~mm}$, DV: $7.0-8.5 \mathrm{~mm}$ ), and a stainless-steel RE of the stimulating electrode was placed under the skin. A monophasic current stimulation pulse was generated by the Master- 8 stimulator (Iso-Flex/Master-8, AMPI) and delivered to the MFB target. Recordings were made at least $30 \mathrm{~min}$ after electrode insertion to allow for tonic DA levels to equilibrate. All the experiments were performed inside a Faraday cage to avoid electromagnetic interference. To verify in vivo detection of DA, nomifensine, a DA uptake inhibitor, was injected intraperitoneally (7 $\mathrm{mg} / \mathrm{kg}) .{ }^{(37)}$

\section{Results and Discussion}

\subsection{Morphological and structural characterization}

As shown in Fig. 2(a), the surface of bare Au sites was very smooth. Figure 2(b) shows that after the modification by AuNPs, the surface of Au sites was densely covered by various AuNPs of irregular shape. As for AuPt-alloy-nanoparticle-modified Au sites [Fig. 2(c)], the surface of $\mathrm{Au}$ sites was uniformly and densely covered by cauliflower-like AuPt alloy nanoparticles possessing a diameter of about $200 \mathrm{~nm}$. In order to further study the morphological characterization of the prepared AuPt alloy nanoparticles, a SEM image with higher magnification was obtained. As shown in the inset image of Fig. 2(c), the obtained AuPt alloy nanoparticles with many different sizes of pores possessed very rough surfaces and exhibited cauliflower-like shapes, which was mainly due to the chemical etching of the $\mathrm{Cu}$ component from the $\mathrm{Au}-\mathrm{Pt}-\mathrm{Cu}$ trimetallic nanoparticles. It was believed that these special properties of AuPt alloy nanoparticles would drastically decrease the impedance of electrode sites, enhance electrocatalytic activity, and promote electron transfer rates.

In order to further study the structural characterization of the prepared AuPt alloy nanoparticles, the XRD patterns were obtained on a diffractometer with $\mathrm{Cu} \mathrm{K} \alpha$ radiation $(\lambda$ $=0.15418 \mathrm{~nm}$ ). As shown in Fig. 2(d), three obvious peaks appearing at 39.2, 45.5, and $66.2^{\circ}$ corresponded to (111), (200), and (220) planes of AuPt alloy nanoparticles, respectively, which showed that the obtained AuPt alloy possessed a face-centered cubic structure. It is well known that the (111), (200), and (220) planes of pure Au nanoparticles and Pt nanoparticles correspond 


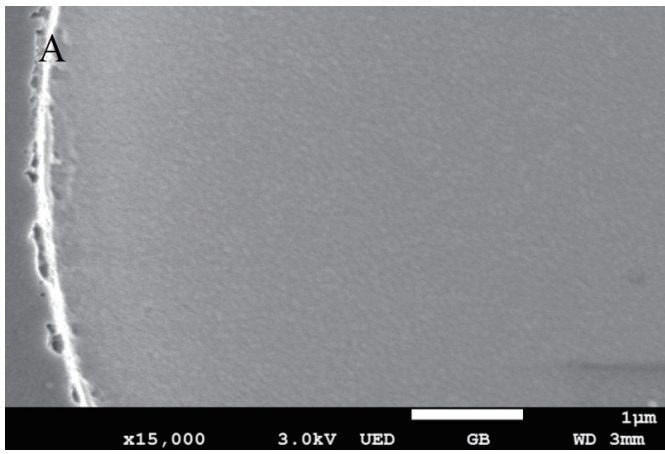

(a)

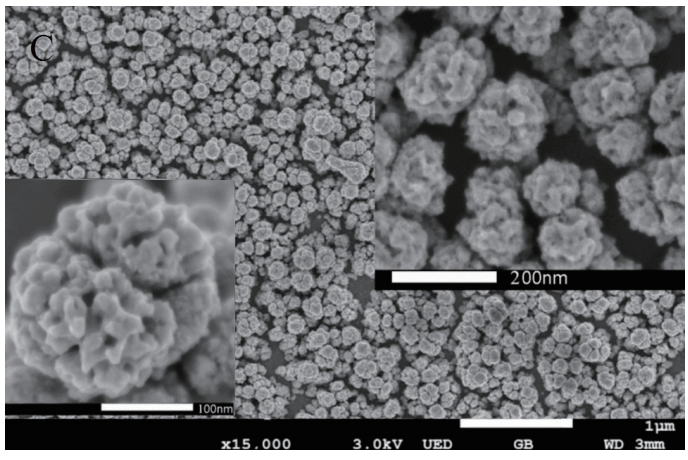

(c)

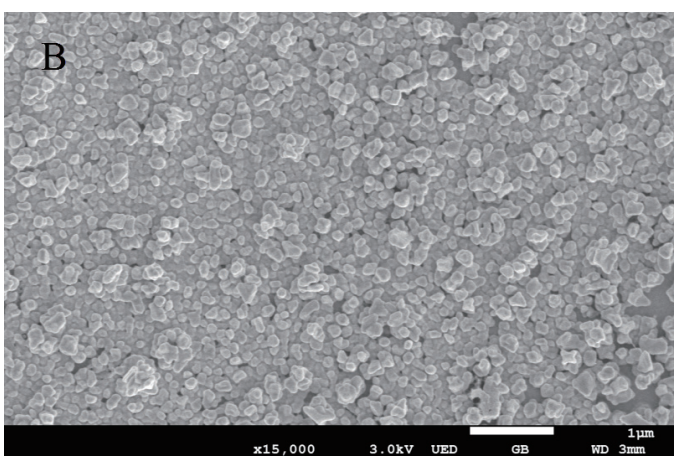

(b)

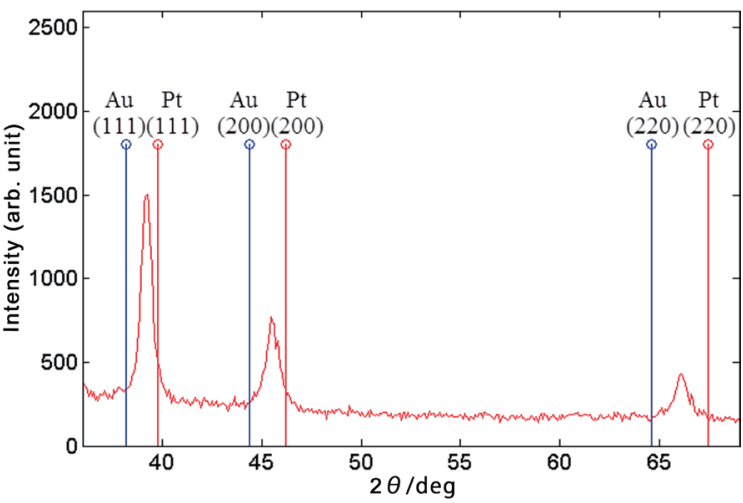

(d)

Fig. 2. (Color online) (a) SEM image of bare Au electrode site surface, (b) SEM image of AuNPs, (c) SEM image of AuPt alloy nanoparticles with nanoporosity, and (d) XRD patterns of the resulting AuPt alloy nanoparticles.

to the peaks at $38.2,44.4$, and $64.6^{\circ}$ and at $39.8,46.2$, and $67.5^{\circ}$, respectively. Figure 2(d) indicates that the (111) plane at $39.2^{\circ}$ of AuPt alloy was located between the (111) plane at $38.2^{\circ}$ of Au nanoparticles and the (111) plane at $39.8^{\circ}$ of Pt nanoparticles, which demonstrated that the prepared AuPt nanoparticles were a single-phase alloy rather than two separated phases of $\mathrm{Pt}$ and Au.

\subsection{Electrochemical characterization}

The electrochemical characterization of the prepared AuPt alloy nanoparticles was studied in detail. Firstly, the electrochemical properties of three kinds of microelectrode sites (bare Au sites, and AuNPs-modified and AuPt-alloy-nanoparticle-modified sites) were compared in 0.5 $\mathrm{M} \mathrm{H}_{2} \mathrm{SO}_{4}$ using $\mathrm{CV}$ at a scan rate of $50 \mathrm{mV} / \mathrm{s}$. As shown in Fig. 3, the cyclic voltammograms of the bare Au site (curve c) and AuNPs-modified site (curve b) indicated that there was only one potential peak at around $+1.06 \mathrm{~V}$ assigned to the reduction of $\mathrm{Au}$ oxide species. However, the cyclic voltammogram of the AuPt-alloy-nanoparticle-modified Au site (curve a) implied that the potential peaks at around +1.06 and $+0.48 \mathrm{~V}$ were assigned to the reduction of Pt oxide species and $\mathrm{Au}$ oxide species, respectively. ${ }^{(38)}$ The peaks ranging from -0.08 to $+0.12 \mathrm{~V}$ were 


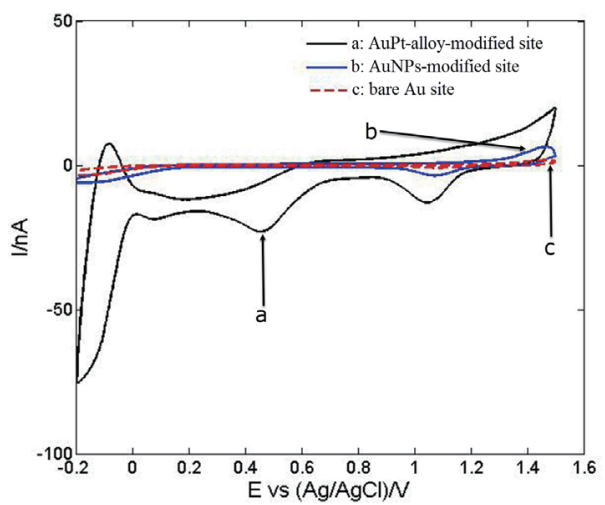

(a)

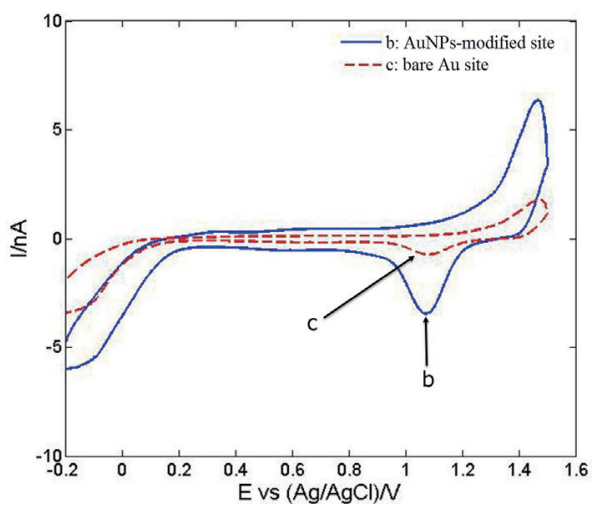

(b)

Fig. 3. (Color online) Bare Au microelectrode site (curve c) and Au microelectrode sites modified with AuNPs (curve b) and rough-surfaced AuPt alloy nanoparticles (curve a) in $0.5 \mathrm{M} \mathrm{H}_{2} \mathrm{SO}_{4}$ at scan rate of $50 \mathrm{mV} / \mathrm{s}$.

due to the hydrogen adsorption/desorption reactions. These results confirmed that there existed $\mathrm{Au}$ and Pt elements in the prepared AuPt alloy nanoparticles. In addition, compared with the bare $\mathrm{Au}$ site and AuNPs-modified site, the AuPt-alloy-nanoparticle-modified Au site showed the highest metal electrochemical catalytic area because the cyclic voltammogram of the AuPtalloy-nanoparticle-modified Au site exhibited the largest reduction current of Au oxide species at around $+1.06 \mathrm{~V}$.

The electrochemical characterization of the obtained $\mathrm{Au}$ sites was further studied in $2 \mathrm{mM}$ $\left[\mathrm{Fe}(\mathrm{CN})_{6}\right]^{3-/ 4-}$ using CV. Figure 4(a) presents the representative cyclic voltammogram of a bare $\mathrm{Au}$ site (curve a), and microelectrode sites modified with AuNPs (curve b), AuPt alloy nanoparticles (curve c), and Nafion/AuPt alloy nanoparticles (curve d). The bare Au site (curve a) showed small redox peak currents, indicating that the bare Au site possessed a poor electron transfer rate. After modificaton with AuNPs (curve b), there appeared a pair of well-resolved peaks at the AuNPs-modified microelectrode site with a peak potential separation of around $178 \mathrm{mV}$. In addition, the current responses evidently increased compared with that of the bare Au site, which demonstrated that the AuNPs could greatly enhance electric conductivity. However, the peak currents of the AuPt-alloy-nanoparticle-modified Au site (curve c) further increased, and the peak potential separation significantly decreased to $99 \mathrm{mV}$, which showed that nanoporous AuPt alloy nanoparticles could provide better electric conductivity and faster electron transfer rates than AuNPs, as a result of the excellent conductivity and large surface area of nanoporous AuPt alloy nanoparticles. However, the Au site modified with Nafion/ nanoporous AuPt alloy nanoparticles (curve d) showed a smaller oxidation peak current than did the nanoporous-AuPt-alloy-nanoparticle-modified Au site (curve c), because Nafion is a cation exchange polymer and can reject the negatively charged species $\left[\mathrm{Fe}(\mathrm{CN})_{6}\right]^{3-/ 4-}$, suggesting that the Nafion film was successfully formed on the microelectrode site by the electropolymerization method.

In addition, $\mathrm{CV}$ at different scan rates was used to further investigate the electrochemical properties of the obtained AuPt-alloy- and AuNPs-modified Au sites in $2 \mathrm{mM}\left[\mathrm{Fe}(\mathrm{CN})_{6}\right]^{3-/ 4-}$ 


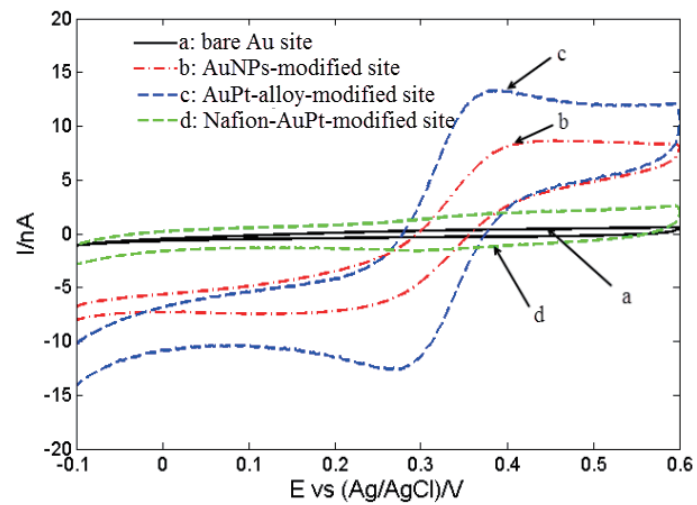

(a)

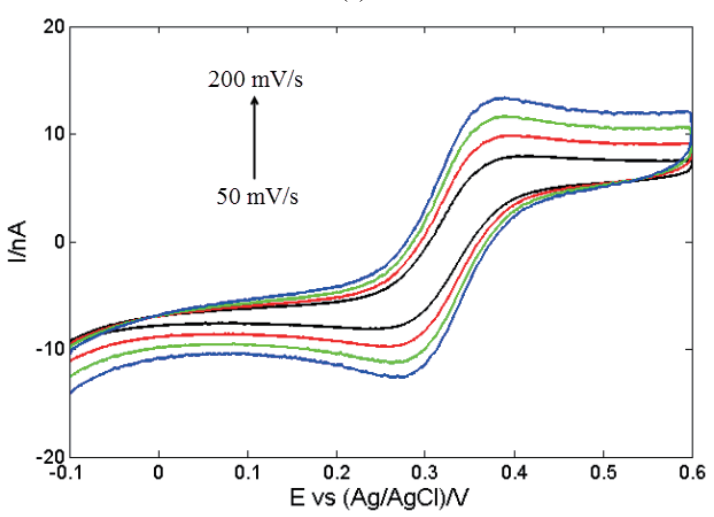

(c)

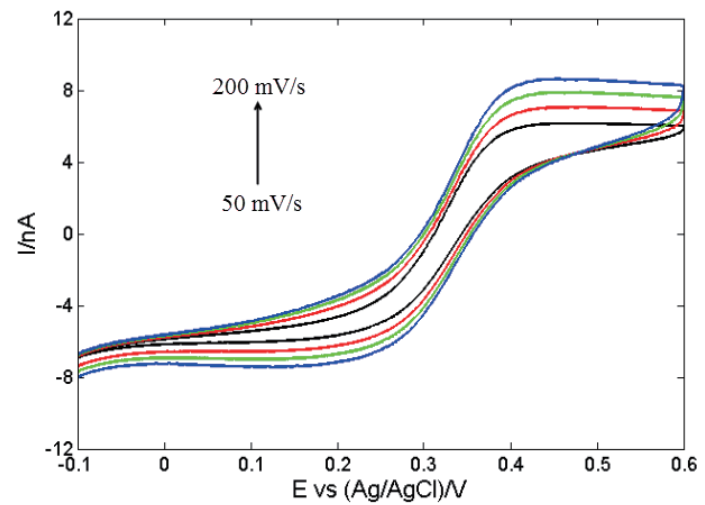

(b)

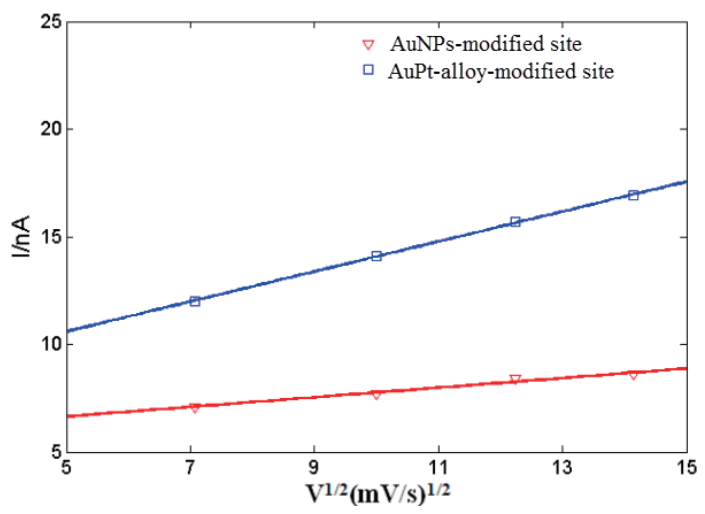

(d)

Fig. 4. (Color online) (a) Cyclic voltammograms of bare Au site (curve a) and microelectrode sites modified with AuNPs (curve b), AuPt alloy nanoparticles (curve c), and Nafion/AuPt alloy nanoparticles (curve d) in $2 \mathrm{mM}$ $\left[\mathrm{Fe}(\mathrm{CN})_{6}\right]^{3-/ 4-}$ at scan rate of $200 \mathrm{mV} / \mathrm{s}$. Cyclic voltammograms of (b) AuNPs and (c) rough-surfaced AuPt-alloynanoparticle-modified sites in $2 \mathrm{mM}\left[\mathrm{Fe}(\mathrm{CN})_{6}\right]^{3-/ 4-}$. Scan rate: 50, 100, 150, and $200 \mathrm{mV} / \mathrm{s}$. (d) Plots of linear relationship between anodic peak currents $\left(I_{p a}\right)$ and square root of the scan rates.

prepared with 0.1 M KCl solution. As shown in Figs. 4(b) and 4(c), both AuPt-alloy- and AuNPs-modified Au sites exhibited the following characteristics. The peak potentials did not vary with increasing scan rate and were almost a fixed value. The amplitude of anodic peak currents was almost equal to that of cathodic peak currents. These properties implied that a quasi-reversible electrochemical process occurred at both AuPt-alloy- and AuNPs-modified $\mathrm{Au}$ sites in $2 \mathrm{mM}\left[\mathrm{Fe}(\mathrm{CN})_{6}\right]^{3-/ 4-}$. Moreover, the relationship between anodic peak currents and scan rates was studied. As shown in Fig. 4(d), for both AuPt-alloy- and AuNPs-modified Au sites, there existed a linear relationship between the anodic peak currents and the square root of the scan rates ranging from 50 to $200 \mathrm{mV} / \mathrm{s}$, which implied that the electrochemical reactions at both AuPt-alloy- and AuNPs-modified Au sites in $2 \mathrm{mM}\left[\mathrm{Fe}(\mathrm{CN})_{6}\right]^{3-/ 4-}$ were mainly occupied by a diffusion-controllable process. ${ }^{(20)}$ For the diffusion-controllable process and quasireversible responses, electroactive surface area (ESA) could be computed using the RandlesSevcik equation: ${ }^{(39,40)}$ 


$$
I_{p}=2.69 \times 10^{5} A \cdot D^{\frac{1}{2}} \cdot n^{\frac{3}{2}} \cdot v^{\frac{1}{2}} \cdot C,
$$

where $I_{p}$ stands for anodic or cathodic peak current, and $n$ represents the electron number of electrochemical responses $\left(n=1\right.$ for $\left.\left[\mathrm{Fe}(\mathrm{CN})_{6}\right]^{3-/ 4}\right)$. $C$ stands for the concentration $\left(\mathrm{mol} \mathrm{cm}^{-3}\right)$ of $\left[\mathrm{Fe}(\mathrm{CN})_{6}\right]^{3-/ 4-}$ and $D$ represents the diffusion coefficient $\left(\mathrm{cm}^{2} \mathrm{~s}^{-1}\right)$ of $\left[\mathrm{Fe}(\mathrm{CN})_{6}\right]^{3-/ 4-}$ (here, $D=6.7$ $\times 10^{-6}$ at $\left.25^{\circ} \mathrm{C}\right), v$ and $A$ stand for the scan rate $\left(\mathrm{V} \mathrm{s}^{-1}\right)$ and ESA of sites, respectively.

As shown in Fig. 4(d), $I_{p a}$ was proportional to $v^{1 / 2}$, and then the ESA for both AuPt-alloyand AuNPs-modified $\mathrm{Au}$ sites could be computed from these linear relationships. Results showed that the estimated ESA values were 6247.4 and $16301 \mu \mathrm{m}^{2}$ for AuNPs- and AuPt-alloymodified Au sites, respectively. However, the geometric area of a round unmodified Au site with a diameter of $50 \mu \mathrm{m}$ was computed to be $1963.5 \mu \mathrm{m}^{2}$, which was only $1 / 8$ of the ESA of the AuPt-alloy-nanoparticle-modified Au site, impliying that AuPt alloy nanoparticles could greatly enhance the roughness of the electrode site and promote electric conductivity. It is believed that these electrochemical properties of nanoporous AuPt alloy nanoparticles could greatly enhance electrocatalytic activity toward DA.

\subsection{Electrocatalytic activity toward DA}

The electrocatalytic activity toward DA of different microelectrodes was compared in $0.1 \mathrm{M}$ PBS ( $\mathrm{pH}=7.4$ ) containing $50 \mu \mathrm{M}$ DA applying $\mathrm{CV}$, and the results are presented in Fig. 5. As shown in Fig. 5, compared with the Nafion-modified bare Au site (curve c), the Nafion/AuNPsmodified site (curve b) showed a larger redox current, indicating that AuNPs could greatly enhance electron transfer rates. As for the Nafion/AuPt-alloy-nanoparticle-modified Au site (curve a), the anodic and cathodic peak currents further increased, which showed that nanoporous AuPt alloy nanoparticles could provide faster electron transfer rates and better electrocatalytic activity toward DA than AuNPs. In addition, the anodic peak potential of the Nafion/AuPtalloy-nanoparticle-modified microelectrode site appeared at about $0.3 \mathrm{~V}$; therefore, a constant potential of $+0.3 \mathrm{~V}$ was applied in amperometric detections of DA.

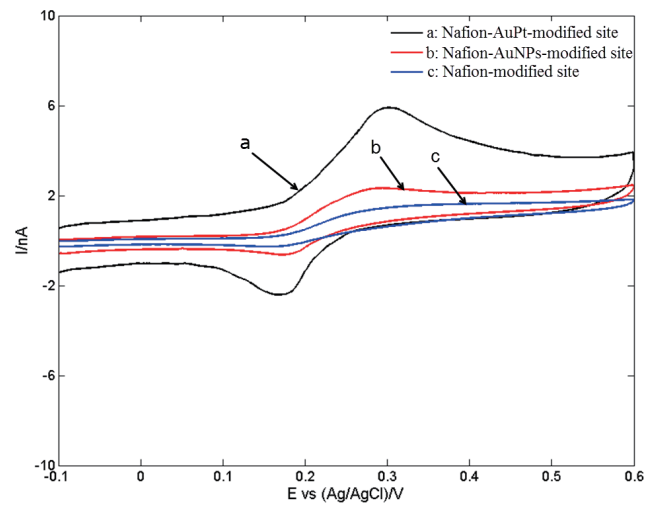

Fig. 5. (Color online) Cyclic voltammograms of microelectrode sites modified with Nafion/AuPt alloy nanoparticles (curve a), Nafion/AuNPs (curve b), and Nafion (curve c) in $50 \mu \mathrm{M}$ DA prepared with $0.1 \mathrm{M} \mathrm{PBS}(\mathrm{pH}=$ 7.4) at a scan rate of $10 \mathrm{~V} / \mathrm{s}$. 


\subsection{Amperometric determination of DA}

Amperometry was adopted to detect DA in 0.1 M PBS $(\mathrm{pH}=7.4)$ at a Nafion/AuPt-alloynanoparticle-modified Au site, by applying $+0.3 \mathrm{~V}$ vs $\mathrm{Ag} / \mathrm{AgCl}$. As shown in Fig. 6(a), the amperometric response current showed a rapid and steep increase with successive addition of DA solution. Figure 6(b) indicates that there exists a linear relationship between DA oxidation currents and DA concentrations varying from 0.05 to $12.05 \mu \mathrm{M}$ with a high sensitivity of $73.4 \pm 3.1$ $\mathrm{pA} / \mu \mathrm{M}$ and a low detection limit of $25 \mathrm{nM}$ (signal-to-noise ratio of 3 ).

It is well known that one of the most important factors that should be taken into consideration in developing in vivo DA electrochemical sensors is the selectivity. This factor is very important because major sources of interference, including AA and DOPAC, also exist in body fluids together with DA and show similar oxidization potentials as that of DA. Therefore, it is significant to test whether these major interferences influence the detection of DA at the obtained Nafion/AuPt-alloy-nanoparticle-modified Au site. As shown in Fig. 7, a constant potential of $+0.3 \mathrm{~V}$ vs $\mathrm{Ag} / \mathrm{AgCl}$ was applied at the prepared DA sensor and $1 \mu \mathrm{M} \mathrm{DA}, 12 \mu \mathrm{M}$

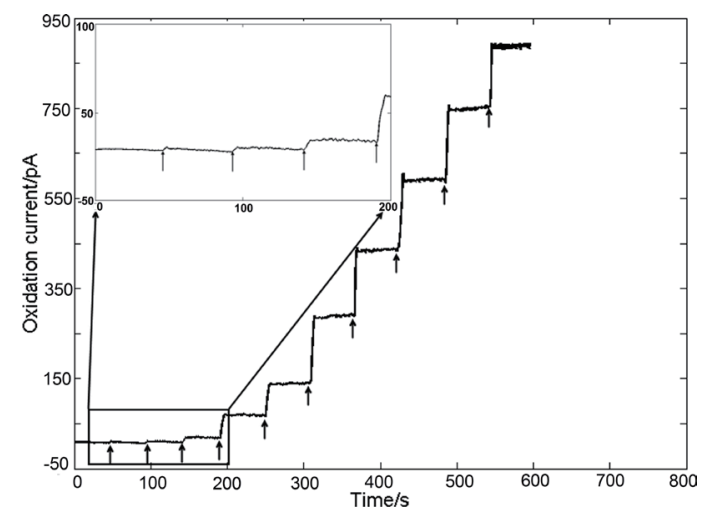

(a)

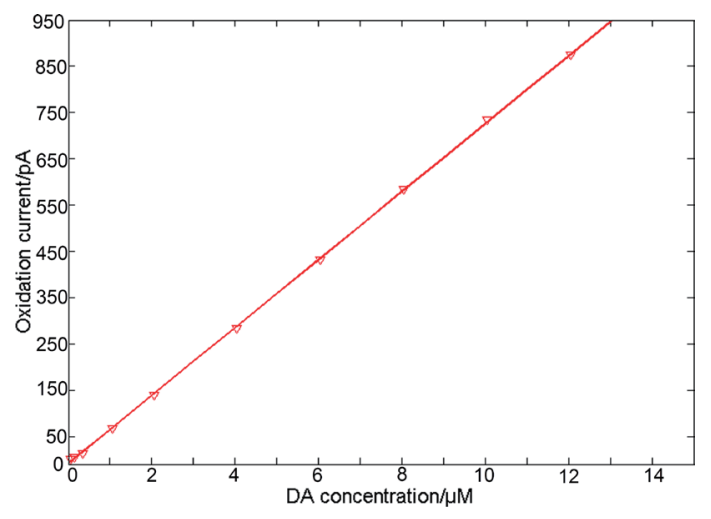

(b)

Fig. 6. (Color online) (a) Amperometric responses of Nafion/AuPt-alloy-nanoparticle-modified microelectrode site with sequential addition of $0.05,0.1,0.2,0.7,1,2,2,2,2$, and $2 \mu \mathrm{M}$ DA in $0.1 \mathrm{M}$ PBS solution ( $\mathrm{pH}=7.4)$ (applied potential: $+0.3 \mathrm{~V}$ vs $\mathrm{Ag} / \mathrm{AgCl}$; background current was subtracted). (b) Linear sensitivity of Nafion/AuPt-modified microelectrode site in terms of oxidation current vs DA concentration.

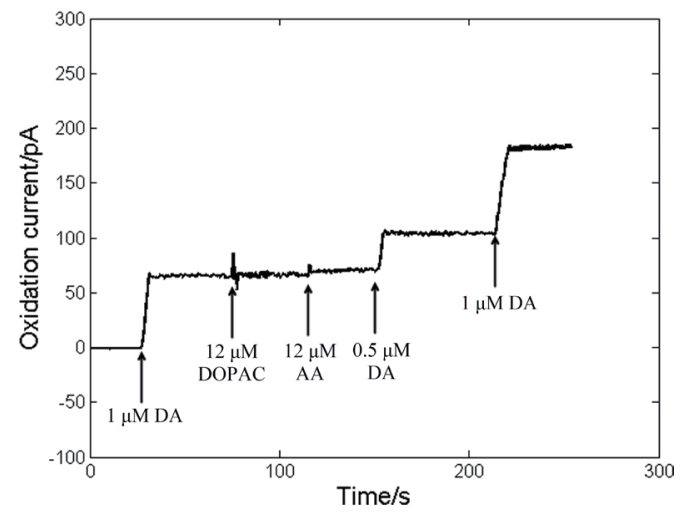

(c)

Fig. 7. Amperometric responses of Nafion/AuPt-alloy-nanoparticle-modified microelectrode site upon sequential addition of $1 \mu \mathrm{M}$ DA, $12 \mu \mathrm{M}$ DOPAC, $12 \mu \mathrm{M} \mathrm{AA}, 0.5 \mu \mathrm{M}$ DA, and $1 \mu \mathrm{M}$ DA in $0.1 \mathrm{M}$ PBS solution ( $\mathrm{pH}=7.4)$ (applied potential: $+0.3 \mathrm{~V}$ vs $\mathrm{Ag} / \mathrm{AgCl}$; background current was subtracted). 
DOPAC, $12 \mu \mathrm{M}$ AA, $0.5 \mu \mathrm{M}$ DA, and $1 \mu \mathrm{M}$ DA were injected successively. Results showed that there was no apparent oxidation current when $12 \mu \mathrm{M}$ DOPAC was injected. However, a small oxidation current appeared with the addition of $12 \mu \mathrm{M} \mathrm{AA}$, and the selectivity ratio of DA over AA was calculated to be $290 \pm 14(n=6)$. The above results indicated that the obtained Nafion/ AuPt-alloy-nanoparticle-modified Au site possessed excellent selectivity for DA determination over major sources of interference.

\subsection{DA recording in striatum of anesthetized rats}

Although the above amperometric measurements show that the proposed microelectrode possesses sufficient sensitivity and selectivity, the feasibility of in vivo DA recording was further verified by recording electrically evoked DA in the striatum of anesthetized rats. In addition, the sensitivity of the proposed Au sites was tested again after in vivo DA recordings and results showed an obvious decrease in DA detection sensitivity from $73.4 \pm 3.1$ to $49.8 \pm$ $0.9 \mathrm{pA} / \mu \mathrm{M}$ after implantation. Therefore, the sensitivity of $49.8 \pm 0.9 \mathrm{pA} / \mu \mathrm{M}$ after implantation was used to calculate the responding DA concentrations.

Following repeated MFB stimulation trials, DA responsive currents were observed. Figures 8 (a) and 8(b) show the recorded in vivo DA responsive currents with electrical stimulation intensities of 300 and $600 \mu \mathrm{A}$, respectively. The calculated maximum DA concentrations at a stimulation intensity of $600 \mu \mathrm{A}$ was $4.08 \pm 0.31 \mu \mathrm{M}$, which was obviously greater than the 0.82 $\pm 0.02 \mu \mathrm{M}$ at a stimulation intensity of $300 \mu \mathrm{A}$ (Student $t$-test, $P=0.002, n=6$ ). The results indicated that higher stimulation amplitudes evoked larger DA oxidation currents. In order to clarify that the observed responsive currents were not mainly due to stimulus artifacts, a DA uptake inhibitor (nomifensine, $7 \mathrm{mg} / \mathrm{kg}$ ) was injected intraperitoneally. ${ }^{(37)}$ As shown in Fig. 8(c), in contrast with the responsive current of the control condition (without nomifensine), the DA reuptake inhibitor could greatly enhance DA responsive currents. The calculated maximum DA concentration involving nomifensine was $2.67 \pm 0.17 \mu \mathrm{M}$, which was obviously greater

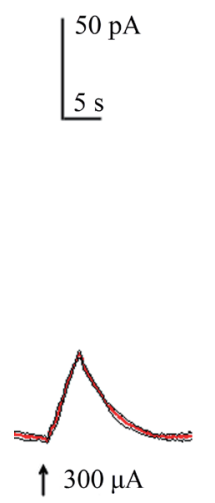

(a)

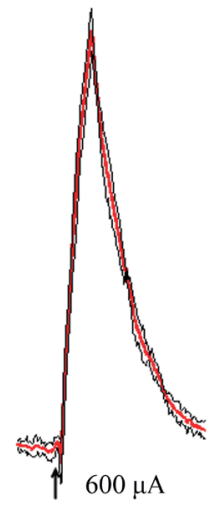

(b)

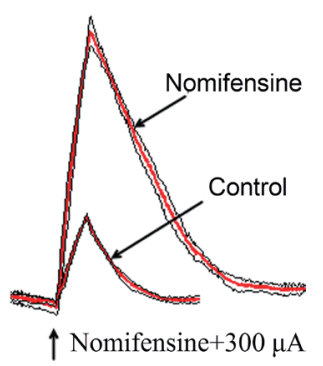

(c)

Fig. 8. (Color online) (a) In vivo DA oxidation currents (average \pm standard deviation, $n=6$ ) in the striatum with electrical stimulation intensity of $300 \mu \mathrm{A}$. (b) In vivo DA oxidation currents (average \pm standard deviation, $n=6$ ) in the striatum with electrical stimulation intensity of $600 \mu \mathrm{A}$. (c) Effect of intraperitoneal administration using nomifensine $(7 \mathrm{mg} / \mathrm{kg})$ in response to electrical stimulation intensity of $300 \mu \mathrm{A}$ (average \pm standard deviation, $n$ =6). In all in vivo DA recordings, a monophasic cathodic current pulse was delivered to the MFB target, and the stimulation frequency and pulse width were $130 \mathrm{~Hz}$ and $100 \mu \mathrm{s}$, respectively. The duration of electrical stimulation was $5 \mathrm{~s}$ in all in vivo DA recordings and the arrows indicate the start of the stimulation. 
than the $0.82 \pm 0.02 \mu \mathrm{M}$ without nomifensine at a stimulation intensity of $300 \mu \mathrm{A}$ (Student $t$-test, $P=0.01, n=6$ ). Moreover, the peak currents involving nomifensine showed a prolonged decline compared with that without nomifensine. Therefore, it was believed that the increased responsive currents and slow decline of peak currents upon nomifensine administration were mainly due to the accumulation of DA concentration in fluids outside of cells, which is consistent with previous reports. ${ }^{(2,7,37)}$ In a word, the above results indicated that amperometry coupled with Nafion/AuPt-alloy-nanoparticle-modified Au sites possessed sufficient feasibility for enabling in vivo recording of DA concentration in the brain of anesthetized rats.

\section{Conclusions}

In this paper, a Nafion/AuPt-alloy-nanoparticle-modified microelectrode array used for in vivo recording of DA in the brain of anesthetized rats was reported. The key element of the prepared microelectrode array used as in vivo DA sensors was the nanoporous AuPt alloy nanoparticles, and in vitro electrochemical measurements showed that AuPt alloy nanoparticles possessed large electroactive surface areas, high conductivity, and greatly enhanced electrocatalytic activity toward DA. Together with the cation exchange polymer Nafion, the resulting Nafion/AuPt-alloy-nanoparticle-modified microelectrode array could greatly reduce the effect of the main DA interferences such as AA and DOPAC. The proposed microelectrode array exhibited a wide linear range of $0.05-12.05 \mu \mathrm{M}$ with a high sensitivity of $73.4 \pm 3.1 \mathrm{pA} / \mu \mathrm{M}$ and a low detection limit of $25 \mathrm{nM}$. The most important step was testing the feasibility of in vivo recording of DA concentration using the proposed microelectrode arrays, and implanted DA recordings in the brain of anesthetized rats demonstrated that the obtained microelectrode array possessed sufficient feasibility for enabling in vivo recording of DA concentration in the brain of an animal model. The developed Nafion/AuPt-alloy-nanoparticlemodified microelectrode array may become a significant research tool for understanding the mechanisms of therapies such as deep brain stimulation (DBS) for PD in animal models.

\section{Acknowledgments}

This work was financially supported by the Natural Science Foundation of Henan Province (16A416009, 2014GGJS-096, 17A535003), the support project for the Disciplinary group of Psychology and Neuroscience, Xinxiang Medical University (2016PN-KFKT-24, 2016PNKFKT-19), the Doctoral Scientific Research Foundation of Xinxiang Medical University (XYBSKYZZ201718), and the Scientific and Technological Project of Henan Province (182102310555, 182102310528).

\section{References}

1 P. Norlin, M. Kindlundh, A. Mouroux, K. Yoshida, and U. G. Hofmann: J. Micromech. Microeng. 12 (2002) 414.

2 M. D. Johnson, R. K. Franklin, M. D. Gibson, R. B. Brown, and D. R. Kipke: J. Neurosci. Meth. 174 (2008) 62.

3 J. J. Burmeister, K. Moxon, and G. A. Gerhardt: Anal. Chem. 72 (2000) 187. 
4 O. Frey, P. D. van der Wal, S. Spieth, O. Brett, K. Seidl, O. Paul, P. Ruther, R. Zengerle, and N. F. de Rooij: J. Neural Eng. 8 (2011) 066001.

5 O. Frey, T. Holtzman, R. M. McNamara, D. E. H. Theobald, P. D. van der Wal, N. F. de Rooij, J. W. Dalley, and M. Koudelka-Hep: Sens. Actuators, B 154 (2011) 96.

6 J. J. Burmeister and G. A. Gerhardt: Anal. Chem. 73 (2001) 1037.

7 J. Njagi, M. M. Chernov, J. C. Leiter, and S. Andreescu: Anal. Chem. 82 (2010) 989.

8 W. Zhang, J. Zheng, J. Shi, Z. Lin, Q. Huang, H. Zhang, C. Wei, J. Chen, S. Hu, and A. Hao: Anal. Chim. Acta 853 (2015) 285.

9 M. Lin: RSC Adv. 5 (2015) 9848.

10 G. Xu, W. Wang, B. Li, Z. Luo, and X. Luo: Microchim. Acta 182 (2015) 679.

11 B. Rezaei, M. K. Boroujeni, and A. A. Ensafi: Biosens. Bioelectron. 66 (2015) 490.

12 P. Pang, F. Yan, H. Li, H. Li, Y. Zhang, H. Wang, Z. Wu, and W. Yang: Anal. Methods 8 (2016) 4912.

13 M. K. Kumar, R. K. V. Prataap, S. Mohan, and S. K. Jha: Microchim. Acta 183 (2016) 1759.

14 N. Yusoff, A. Pandikumar, A. R. Marlinda, N. M. Huang, and H. N. Lim: Sci. Adv. Mater. 7 (2015) 2692.

15 N. G. Mphuthi, A. S. Adekunle, O. E. Fayemi, L. O. Olasunkanmi, and E. E. Ebenso: Sci. Rep. 7 (2017) 43181.

16 M. Velmurugan, R. Devasenathipathy, S. M. Chen, K. Kohila Rani, and S. F. Wang: Electroanal. 29 (2016) 923.

17 H. Song, G. Xue, J. Zhang, G. Wang, B. C. Ye, S. Sun, L. Tian, and Y. Li: Microchim. Acta 184 (2017) 843.

18 C. Wang, J. Li, K. Shi, Q. Wang, X. Zhao, Z. Xiong, X. Zou, and Y. Wang: J. Electroanal. Chem. 770 (2016) 56.

19 E. Haghshenas, T. Madrakian, and A. Afkhami: Anal. Bioanal. Chem. 408 (2016) 2577.

20 Z. Zhao, M. Zhang, X. Chen, Y. Li, and J. Wang: Sensors 15 (2015) 16614.

21 C. E. Zou, J. Zhong, J. Wang, Y. Shiraishi, S. Li, B. Yan, J. Guo, and Y. Du: RSC Adv. 6 (2016) 92502.

22 W. Chu, Q. Zhou, S. Li, W. Zhao, N. Li, and J. Zheng: Appl. Surf. Sci. 353 (2015) 425.

23 S. Palanisamy, B. Thirumalraj, S. M. Chen, M. Ajmal Ali, K. Muthupandi, R. Emmanuel, P. Prakash, and F. M. A. Al-Hemaid: Electroanalysis 27 (2015) 1998.

24 M. Cheng, X. Zhang, M. Wang, H. Huang, and J. Ma: J. Electroanal. Chem. 786 (2017) 1.

25 H. W. Yu, J. H. Jiang, Z. Zhang, G. C. Wan, Z. Y. Liu, D. Chang, and H. Z. Pan: Anal. Biochem. 519 (2017) 92.

26 L. P. Mei, J. J. Feng, L. Wu, J. R. Chen, L. Shen, Y. Xie, and A. J. Wang: Microchim. Acta 183 (2016) 2039.

27 S. Sakthinathan, H. F. Lee, S. M. Chen, and P. Tamizhdurai: J. Colloid Interface Sci. 468 (2016) 120.

28 Y. Li, J. Liu, M. Liu, F. Yu, L. Zhang, H. Tang, B. C. Ye, and L. Lai: Electrochem. Commun. 64 (2016) 42.

29 Y. Liu, P. She, J. Gong, W. Wu, S. Xu, J. Li, K. Zhao, and A. Deng: Sens. Actuators, B 221 (2015) 1542.

30 J. Leng, W. M. Wang, L. M. Lu, L. Bai, and X. L. Qiu: Nanoscale Res. Lett. 9 (2014) 99.

31 A. Balkis and A. P. O'Mullane: Mater. Chem. Phys. 143 (2014) 747.

32 A. Liu, X. Tao, T. Jian, H. Wu, T. Zhao, and W. Tang: Electrochim. Acta 119 (2014) 43.

33 J. Yu, T. Fujita, A. Inoue, T. Sakurai, and M. Chen: Nanotechnology 21 (2010) 85601.

34 L. X. Chen, J. N. Zheng, A. J. Wang, L. J. Wu, J. R. Chen, and J. J. Feng: Analyst 140 (2015) 3183.

35 Z. Zhao, R. Gong, H. Huang, and J. Wang: Sensors 16 (2016) 880.

36 C. Xu, R. Wang, M. Chen, Y. Zhang, and Y. Ding: Phys. Chem. Chem. Phys. 12 (2010) 239.

37 T. C. Tsai, C. X. Guo, H. Z. Han, Y. T. Li, Y. Z. Huang, C. M. Li, and J. J. Chen: Analyst 137 (2012) 2813.

38 S. Shahrokhian and S. Rastgar: Analyst 137 (2012) 2706.

39 Y. Li, R. Yuan, Y. Chai, and Z. Song: Electrochim. Acta 56 (2011) 6715.

40 S. Reddy, B. E. K. Swamy, and H. Jayadevappa: Electrochim. Acta 61 (2012) 78. 